\title{
Study of English Translation Problems in Public Occasions
}

\author{
Jing $\mathrm{Wu}^{1}$, Yun Lin $^{2}$ \\ ${ }^{1}$ Jiangxi Institute of Economic Administrators, Nanchang, Jiangxi, 330038 \\ 54892713@163.com
}

Keywords: Translation Errors; Countermeasures; Public Occasions

\begin{abstract}
With the increasingly frequent in China's foreign exchange, public places of various logos in English translation also are common, but the translation but there spelling, grammatical errors, mistranslations, and many other issues. Translation of the problems in public places classification analysis, can cause everyone's attention, to avoid making the same mistake in translation, thereby creating a healthy public places locales.
\end{abstract}

\section{Introduction}

With the increasingly frequent international exchanges, English gradually penetrated into every aspect of our work and life. English translation appeared in public places more and more, to facilitate foreign friends to show international image. However, non-standard English translation of not only would not achieve the role of good publicity, but also to foreigners misunderstanding, affect the international image of China's foreign exchange.

Slogan and other words are increasingly being translated into English. Our roads, airports, shopping malls, hotels and other public places where there are signs in Chinese and English, scenic tourist brochures are basically English-Chinese version, more and more restaurants are also available in Chinese and English menu. English translation public can show and promote self-image, and accelerate economic development. However, little attention can be found in public places is extremely Translation is not standardized, misspellings, mistranslations and so everywhere. Translation of abuse and misuse are a stumbling block to the progress of social civilization, but also detrimental to China's international image.

\section{Type Error of Translation}

I forgot what to see, "Toilet" (the toilet) makes up "Toilt", so might as well use the "WC", or simply do not translate, a woman's flag has long been popular, you do not need English translation. I remember one day watching $\mathrm{TV}$, the news that there is a tourist attraction to remind visitor attention to public health, the results of the public (public) spelled pubic (genital). This error is really ironic. There are many such examples, it is estimated that when the production went wrong, but it should not be. For one of the most common example, in the provincial capital of Guiyang City, Guizhou Province, over the "Guiyang rental car docking station" on each of the main road, the English translation is: Guiyang City Stop Station. First, according to the State Language Commission on Pinyin writing regulations, Place names should be spelled a word. It is through the United Nations recognized, are subject to the provisions of the text in the Western Chinese place names in the Latin alphabet. Therefore, the "Guiyang" should be translated as Guiyang City or Guiyang, the letter "Y" is not capitalized. Secondly, the word used as a verb stop except for "stop, stop, stop" and other interpretation, but also as a noun, which itself contains "stops" means. So only the word stop "stops" entirely possible. Coupled with the station would be superfluous. Moreover station as a "station" is the solution and usually refers to the buildings, at least slightly the size of the train station, bus station places like, for example, Beijing Railway Station. On the street, there are some English translation is likely to cause serious misunderstanding. For example, downtown "people Dispensary" sign hanging on the English translation for: Great people Drugstore. "The people" with the word can be translated of people on it. Even more serious is the use of the word drugstore, although drugstore there, "pharmacy" means, but in the UK, US drug term refers 
primarily to narcotic drugs, the word appears on the English-language newspaper generally refers to drugs.

Sometimes we actually trying to say very consistent in some public places to see the English translation, which will cause misunderstanding foreign friends, and sometimes have a huge joke. I remember one time to go shopping, the elevator says "Passengers", the following comments in English are "MULTIPLY BY STEPS BEARDKNOW", which in English translates to "multiply, pace, beard, you know." "Terminal" translation Taiyuan Wusu Airport is the waiting-hall rather than international common terminal (building), apparently is a typical example of lied. In addition, a number of commercial and residential near the airport licensing guidelines English translation is also worthy of scrutiny, such as "a certain Garden (Villa)," the English translation with the park, to know that in countries with English as mother tongue, park usually refers to the band there are a lot of tourist attractions open green spaces. For tour of leisure purposes, such as the US National Park and State Park, the famous Yellowstone Nation-hal Park are our familiar and simple.

\section{Error Reasons and Its Solutions}

The above error because the foreign culture varies greatly, originally, the general things on foreigners know little about China, plus four decades of changes in social systems and ideologies, affects every aspect of life, languages as the information, ideas , exchange of ideas and emotional symbol, followed has undergone tremendous changes. A large number of China's unique words and say, in a foreign language is difficult to find ready-made vocabulary to express. We might use some foreigners acceptable Chinese English translation or adopt some practical tips to make the word can convey his ideas.

Building materials can be translated Wuzi Hotel, in fact, our names or building name in Pinyin is very common, and foreigners can accept, such as Beijing's "Dongzhimen Wai Avenue" in English has been using Nongzhimenwaidajie this title; " Jingguang Center "also translated Jinggtlang Center not it? So Ming Palace translated Minggugong some more appropriate. Names dealt translation, it is necessary to cover the range of geographical names redefinition and subdivision. Names mentioned in the "Names Management Regulations", including: natural geographic entity names, administrative units, residential name, professional departments of Taiwan have a sense of place names, station, port, farm and other names. According to this provision, "Beijing Railway Station" can only be labeled "beijinghuochezhan", rather than "Beijing trainstation". I believe that on the street, the road name is spelled standardization and that use Hanyu Pinyin determined to unify the label names, its benefits at least two, one is the "unity" does not appear "is Beijing duckasthesamea as king duck?" The Question: The second is that you can know how to pronounce Pinyin see (or similar pronunciation), helps to reduce language barriers when traveling foreigners in China.

Words in the description of the relationship between the scholars and the style most often cited is the 17th century when English writer Jonathan swift talked about the phrase "the right word to use in the right place." From the stylistic point of view, "the language to be applied to the core of the Arab-Israeli situation is a problem, but a different style, a different genre there are significant differences in the choice of words.", Wang also pointed out that "often requires the use of different stylistic Different words "Translation of the above mentioned tips, we wish to change the body language, translated them:. Take care of the flowers, please (prohibition defloration) This translation with anthropomorphic color, the flowers look as a baby to love and care for people like a baby to love flowers; quiet, please (ban noisy), Keep off the grass (do not step on the lawn) both concise, and standards; while prohibiting spitting, smoking can be translated separately No littling and NO Smoking. and dont no different, it is more often used in a neutral context.

Check translation is wrong is a best way for back translation, such as mentioned above the zone Of no smoking after back-translation is a smoke-free zone. There is a place marked in Yuhuatai scenic area guide map in the "National patriotism education bases, "demonstration here translated into normal base seemed inappropriate, asked a few teachers, do not know what that means. Because the "demonstration" in Chinese meaning is normal, regular, standard, the word normal university, which is also represented by Normal, instead of "demonstration" University. Look at the 
"national demonstration to protect the interests of consumers tourism unit "translation: Nationl Medel unit for Protecting for tourist rights and interest Model as an adjective means exemplary, role models, such as a model student model student. A model farm demonstration farm is a model household demonstration household. The term meodel seems appropriate, but there are discrepancies with the model base of this because it is misleading for the "model base." I think the demonstration on here may be more expressive. Because demonstration plant has been translated into a demonstration factor, demonstration forest is a demonstration forest. Therefore, it should be demonstration base. At least not cause divergence.

English translation in public places is difficult, because most of them are in English or special usage habits. Translated directly from the Chinese past literally, often sudden, a lot of jokes. Another point to make general translator embarrassment is that for such WcpC, lavatory, toilet, bathroom, restroom and washroom and so on, or the vast majority of English-English dictionary can only explain its meaning directly, without explanation on its usage difference, so that the translator confused. Regardless of lavatory or toilet because the toilet is usually both, but also vanity, bathtub and other facilities, some restaurants in the only toilet and wash basin also write on lavatory doors or toilet is not appropriate, because if one of the women need makeup. And into this toilet, there will be a feeling of being cheated.

Guiyang downtown "people Dispensary" translated Great People Drugstore. The word people on it, the more serious is the drugstore, although a "pharmacy" means, but the word in the Anglo-American drug mainly refers to narcotics or drugs. Therefore, in order to meet the English habit user pharmacy. More appropriate.

\section{Conclusions}

English translations errors in public places are tourism environment, but also a part of the investment environment is sloppy. Because, first, public places English is designed to allow foreigners to see if these English translation neither fish nor fowl, not only would not achieve the tips or help to foreigners the role, but to foreigners a bad impression, and then Effect of a hotel, a park, and even the image of a city, can be described without his benefit, served its victims. Second, public spaces are generally more concentrated population and flow faster place, wrong English appear in these places, are learning English for the Chinese people, especially students, is misleading. Most beginners because there is no ability to identify, see openly hanging in public places in English, few doubt its accuracy, something wrong is for beginners as things look right, then repeated the baseless assertion, the harm is not to be underestimate. In this sense, the use of incorrect English in public place is a kind of environmental pollution, but also the pollution of the English language.

\section{Acknowledgements}

Period results of the fund project: "Standardization research of sign translation in Jiangxi Province", 2014 Humanities and Social Science Research Project of Jiangxi Institutes of Higher Education (project code: YY1401)

\section{References}

[1] Cheng Zhihua. Thinking Conversion on EC Translation. Minxi Vocational University, 2001, (1).

[2] Zhao Xiang. Cultural Differences and Language in English Language Translation Identification. Language Teaching, 2006, (2).

[3] Xuzhi Heng. Public Signs Translation Error Analysis and Translation Strategies. Jilin University, 2007, (4). 